\title{
МИКРОПАЛЕОНТОЛОГИЧЕСКАЯ ХАРАКТЕРИСТИКА СТРАТОТИПИЧЕСКИХ РАЗРЕЗОВ НИЖНЕГО КЕМБРИЯ ЭСТОНИИ
}

Разрезы кембрийских отложений Эстонии, выходящих на поверхность вдоль южного берега Финского залива и в пересекающих глинт долинах, являются издавна эталонными для большей части ВосточноЕвропейской платформы. Здесь находятся также стратотипические разрезы кембрийских свит приглинтовой структурно-фациальной зоны, указанные еще А. Эпиком (Öpik, 1933). Именно по данным изучения этих обнажений была составлена кембрийская часть унифицированной схемы MCK (Решения ..., 1965). И несмотря на то, что в настоящее время для отдельных районов платформы созданы местные стратиграфические схемы, северо-эстонские разрезы не утратили своего опорного значения и по-прежнему широко используются при корреляционных построениях. В связи с этим представляется весьма важным изучение кембрийских свит приглинтовой зоны Эстонии и в микропалеонтологическом аспекте, ибо в этом отношении стратотипические разрезы их до сих пор изучены слабо. Литературные данные по этому району (Тимофеев, 1959; Наумова, 1968; Умнова, Фандерфлит, 1971) весьма скудны, часто противоречивы и не дают конкретного представления о развитых здесь комплексах акритарх, которые в настоящее время все шире используются при корреляции кембрийских разрезов платформы на больших расстояниях и в различных структурно-фациальных зонах (Волкова, 1968; Кирьянов, 1969; Розанов и др., 1969; Биркис и др., 1970). Несколько более подробной является лишь работа Н. А. Волковой (1968), охватывающая несколько скважин Эстонии, однако в ней отсутствуют материалы, касающиеся непосредственно стратотипических разрезов.

Учитывая сказанное, авторами настоящего сообщения было предпринято исследование акритарх в стратотипических разрезах Эстонии, при этом использовались материалы как соответствующих естественных обнажений, так и скважин, специально пробуренных Институтом геологии АН ЭССР для восполнения недостающих в обнажениях интервалов разреза.

Всего нами исследовано 44 образца горных пород из четырех разрезов (рисунок). Из них 23 содержали имеющие стратиграфическое значение акритархи; 20 образцов оказались «пустыми» и один содержал лишь лейосферидии, не позволяющие определить возраст вмещающих отложений. Акритархи не были найдены только в алевролитах тискреской свиты. Все другие подразделения, содержавшие слои глин и алевролитов с большой примесью пелитовых частиц, были охарактеризованы 


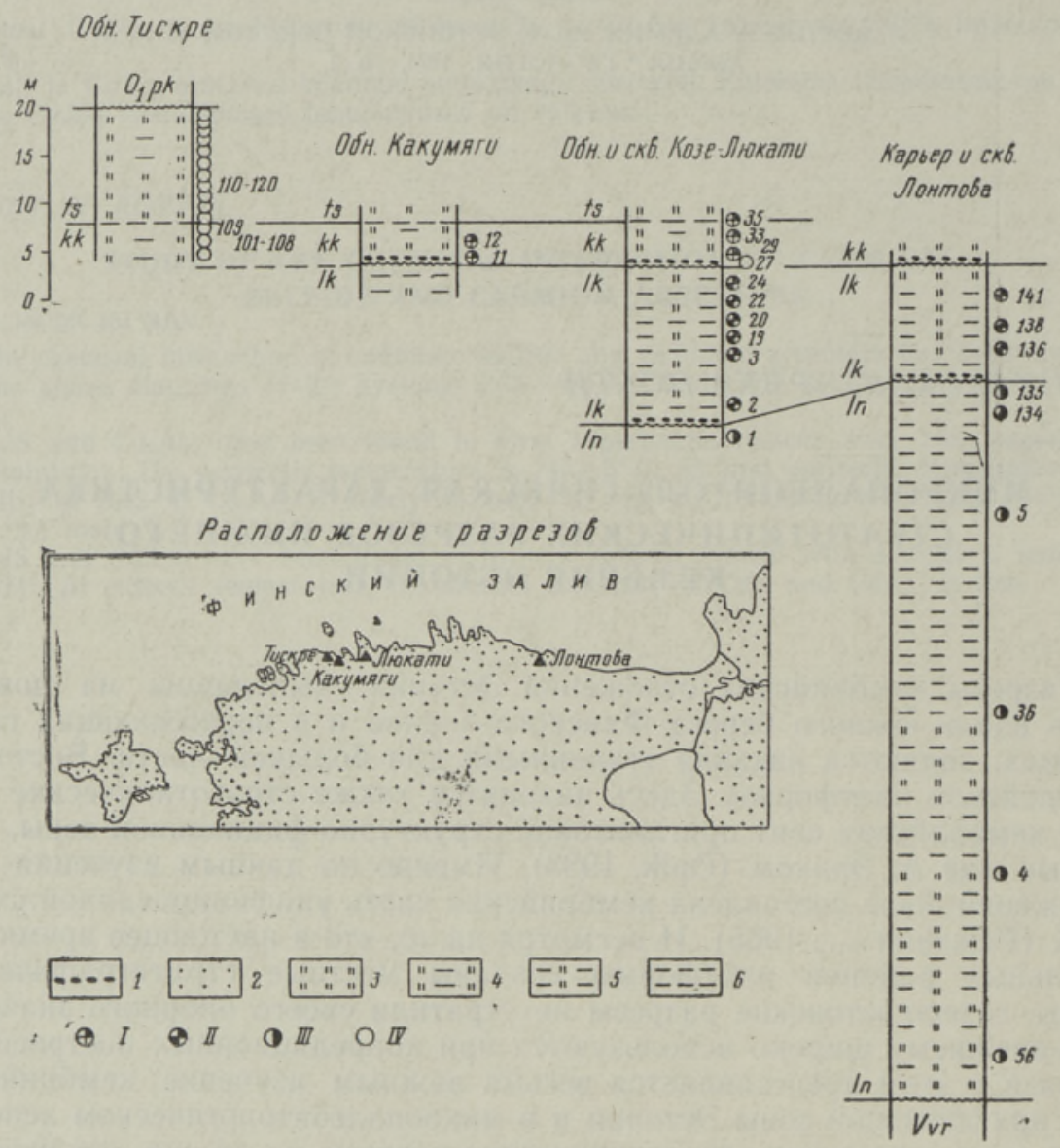

Схема размешэния изученных проб по стратотипическим разрезам нижнего кембрия Эстонии.

1 - конгломерат, 2 - песчаник, 3 - алевролит, 4 - пелитистый и пелитовый алевролит, 5 - алевритовая глина, 6 - глина и алевритистая глина: $I$ - обедненный люкатиский комплекс, II - люкатиский комплекс, III лонтоваский комплекс, $I V$ - образцы, не содержащие акритарх.

Цифры рядом с кружками обозначают номера проб.

микрофоссилиями. Кроме лонтоваской и люкатиской свит, акритархи были выделены также из какумягиской пачки, рассматриваемой в последние годы эстонскими геологами в качестве базальных слоев тискреской свиты (Мардла и др., 1968; Менс, Пиррус, 1972; Кала, 1972).

Все сделанные нами определения сведены в табл. 1, где показано процентное соотношение разных видов акритарх по отдельным пробам. На рисунке указаны места взятия проб в разрезах, а в табл. 2 сведены данные по стратиграфическому распространению акритарх и основных руководящих форм макрофауны в изученных разрезах.

Результаты исследований можно представить в виде следующих выводов.

1. Отложения стратотипических разрезов Лонтова, Люкати и Какумяги имеют богатую микропалеонтологическую характеристику, позволяющую определить их стратиграфический диапазон и выяснить положение этих разрезов относительно установленных к настоящему времени основных рубежей в развитии акритарх. 


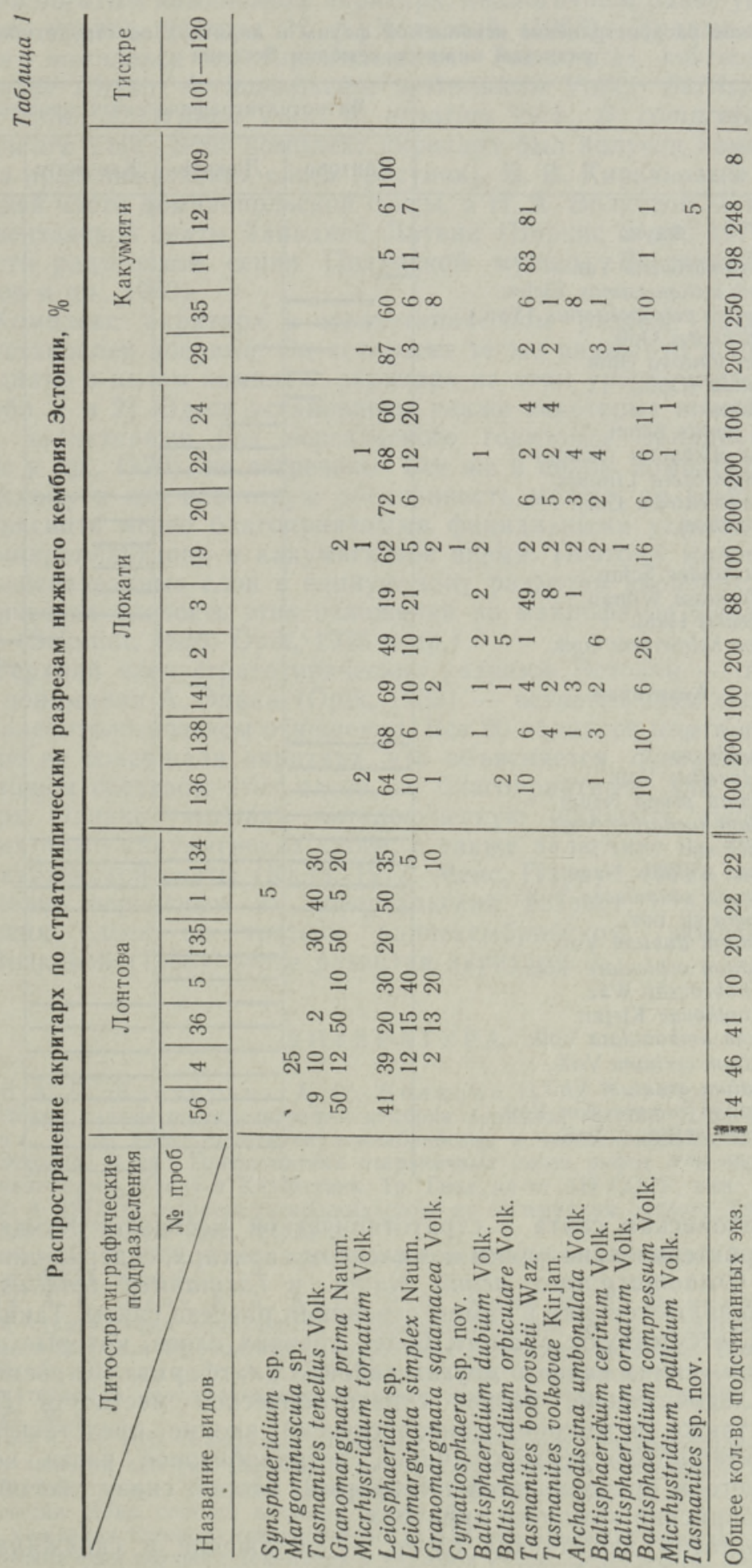


Таблица 2

Вертикальное распространение ископаемой фауны и акритарх по стратотипическим разрезам нижнего кембрия Эстонии

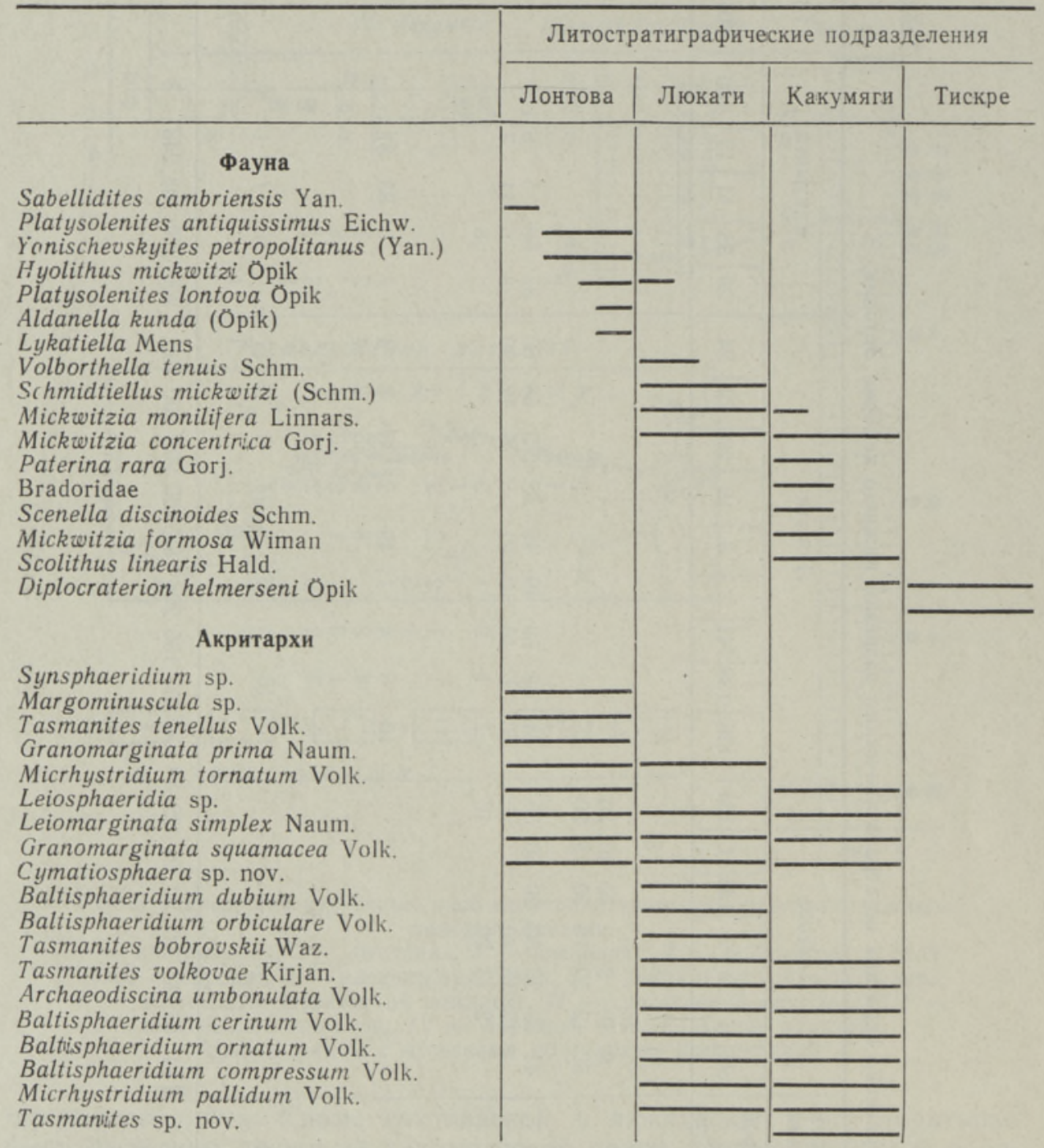

2. Лонтоваская свита в стратотипической местности Кунда (Лонтова) охарактеризована одним комплексом акритарх, содержащим видыиндексы Granomarginata prima Naum. и Tasmanites tenellus Volk., которые появляются уже в самом основании разреза свиты. Таким обра. зом, здесь отсутствуют аналоги более древних слоев, которые слагают низы толщи «синих глин» в других районах платформы (Кирьянов, 1969 и др.). Следовательно, разрез стратотипической местности Лонтова является также и микропалеонтологически вполне представительным для характеристики верхнего члена дотрилобитовой части кембрия, содержащего в пределах всей платформы второй снизу обособленный раннекембрийский комплекг акритарх.

3. Стратотип люкатиских слоев - обнажение и скважина КозеЛюкати в пригороде Таллина - снизу доверху охарактеризован одно- 
типным и богатым комплексом акритарх, аналогичным ранее указанному для этого уровня кембрия Н. А. Волковой (1968). Видами-индексами для этого комплекса акритарх являются Tasmanites bobrovskii Waz., T. volkovae Kirjan. Archaeodiscina umbonulata Volk., Baltisphaeridium dubium Volk., B. cerinum Volk., B. ornatum Volk., B. compressum Volk., B. orbiculare Volk. Этот комплекс акритарх был получен нами из большинства проб люкатиских слоев (рисунок), В. В. Кирьяновым (1969) из верхней части доминопольской свиты, а Н. А. Волковой - из нижней пачки вентавской свиты Западной Латвии (Биркис и др., 1970) и нижней части радзинской серии Подляской мульды Восточной Польши (Розанов и др., 1969).

4. Комплекс акритарх в стратотипическом разрезе какумягиских слоев установлен впервые. Он содержит те же виды, что и люкатиские слои, однако в целом комплекс акритарх на этом уровне несколько беднее (табл. 1 и 2). Здесь установлены также некоторые новые виды, но формы, характерные для вергальского горизонта Западной Латвии (Биркис и др., 1970), не встречены. Все же в целом комплекс близок к люкатискому и его некоторую обедненность можно, по всей вероятности, объяснить менее благоприятными фациальными условиями погребения микропланктона в какумягиское время. Поэтому можно объединить вышеназванные слои в единую зону развития акритарх. Биостратиграфическая близость этих отложений по макрофауне была известна раньше (Schmidt, 1888; Öpik, 1933 и др.).

5. Верхний член стратотипических разрезов Эстонии - тискреские слои в понимании А. Эпика (Öрik, 1933) - остается пока «немым» и в микропалеонтологическом отношении. Все 20 образцов из его стратотипа в Тискре не содержали акритарх, что объясняется, очевидно, песчаноалевритовым составом этих слоев, не благоприятным для сохранения акритарх. Однако учитывая литологическую общность тискреских и лежащих ниже какумягиских слоев, а также залегание их под отложениями курземской свиты (Кала, 1972; Менс, Пиррус, 1972), можно считать вполне вероятным их довергальский возраст, т. е. образование тискреских слоев на третьем раннекембрийском, люкатиском по Н. А. Волковой (1968), этапе развития акритарх.

\section{Л И ТЕ Р А Т У Р А}

Биркис А. П., Брангулис А. П., Волкова Н. А., Розанов А. Ю. 1970. Новые данные по стратиграфии кембрия Западной Латвии. ДАН 195, № 4,

В олков а Н. А. 1968. Акритархи докембрийских и нижнекембрийских отложений Эстонии. В кн.: Проблематика пограничных слоев рифея и кембрия Руоской платформы, Урала и Қазахстана. Тр. Геол. ин-та АН СССР, вып. 188.

К ал а Э. А. 1972. О возрасте тискреских слоев по материалам острова Хийумаа. Изв. АН ЭССР, Хим. Геол., 21, № 3.

К ир я н о в В. В. 1969. Схема стратиграфии кембрийских отложений Волыни. Геол. ж., XXIX, вып. 5.

Мардла А. К., Менс К. А., Кала Э. А., Каяк К. Ф., Эрисалу Э. 1968. К стратиграфии кембрийских отложений Эстонии. В кн.: Стратиграфия нижнего палеозоя Прибалтики и корреляция с другими районами. Вильнюс.

М енс К. А., Пир рус Э. А. 1972. Новые данные о возрасте тискреских слоев по матерналам северо-западных разрезов Эстонии. Изв. АН ЭССР, Хим. Геол., 21, № 3.

Н а у м о в а С. Н. 1968. Зональные комплексы растительных микрофоосилий докембрия и нижнего кембрия Евразии и их стратиграфическое значение. В кн.: Стратиграфия нижнего палеозоя Центральной Европы. Междунар. геол. конгр., XXIII сессия. Докл. советск. геологов, пробл. 9.

Решение межведомственного совещания по разработке унифицированных стратиграфических схем верхнего докембрия и палеозоя Русской платформы, 1962. ВСЕГЕИ, Л., 1965. 
Розанов А. Ю., Миссаржевский В. В., Волкова Н. А., Воронова А.Г. Крылов И. К., Келлер Б. М., Королюк И. К., Лендзион К., Мих. н я к Р., Пы х в в а Н. Г., С и доро в А. Д. 1969. Томмотский ярус и проблема нижней границы кембрия. Тр. Геол. ин-та АН СССР, вып. 206.

Т и мо фее в Б. В. 1959. Древнейшая флора Прибалтики и ее стратиграфическое значение. Тр. ВНИГРИ, вып. 129.

У мнова Н. И., Фандерфлит Е. К. 1971. Комплексы акритарх кембрийских и нижнеордовикских отложений запада и северо-запада Русской платформы. В кн.: Палинологические исследования в Белоруссии и других районах СССР. Минск.

$\mathrm{Schmidt} \mathrm{F.} \mathrm{1888.} \mathrm{Uber} \mathrm{eine} \mathrm{neuentdeckte} \mathrm{untercambrische} \mathrm{Fauna} \mathrm{in} \mathrm{Estland.} \mathrm{Mim.} \mathrm{Imp.}$ Acad. Sci. St. Petersb., Sér. 7, 36, Nr. 2.

Óp ik A. 1933. Uber Scolithus aus Estland. Acta et Comm. Univ. Tartu, XXIV, Nr. 3, Tartu Ulikooli Geol. Inst. Toimet., Nr. 29.

Литовский научно-исследовательский геологоразведочный институт

Поступила в редакцию $19 /$ X 1972

Ннститут геологии

Академии наук Эстонской ССР

\section{T. JANKAUSKAS, ERIKA POSTI}

\section{EESTI ALAMKAMBRIUMI STRATOTUUPSETE LÄBILÖIGETE MIKROPALEONTOLOOGILINE ISELOOMUSTUS}

Artiklis on esitatud andmed akritarhide kooslustest lontova, lükati ja kakumäe stratotüüpsetes läbilōigetes (joon.). Lontova kihistu läbilōikes esinevad kōigis proovides tüüpvormid Granomarginata prima Naum. ja Tasmanites tenellus Volk., mis viitavad rovno kihtide analoogide täielikule puudumisele siin (tab. 1,2). Lükati kihistikus on akritarhide kompleks rikkalikum nii liigiliselt kui ka hulgaliselt, sisaldades Tasmanites bobrovskii Waz.,'T. volkovae Kirjan., Archaeodiscina umbonulata Volk., Baltisphaeridium dubium Volk., B. cerinum Volk., B. ornatum Volk., B. compressum Volk., B. orbiculare Volk. Akritarhide kompleks kakumäe kihistiku stratotüüpsest läbilōikest sarnaneb eelmisele kompleksile, kuid on liikidelt mõnevōrra vaesem. Lisaks esineb siin senikirjeldamata vorm perekonnast Tasmanites, Tiskre kihtidest võetud proovid akritarhe ei sisaldanurl.

\section{T. JANKAUSKAS, ERIKA POSTI}

\section{MICROPALEONTOLOGICAL CHARACTERISTIC OF THE STRATOTYPE SECTIONS OF THE ESTONIAN LOWER CAMBRIAN}

The authors present the distribution of acritarchs in the Lontova, Lükati and Kakumägi stratotype sections (Fig.). Granomarginata prima Naum. and Tasmanites tenellus Volk, are typical of the Lontova Formation, and their presence in the lowermost part of the Lontova stratotype section shows that the Rovno Beds are missing here (Tab. 1, 2). Tasmanites bobrovskii Waz., T. volkovae Kirjan., Archaeodisoina umbonulata Voik., Baltisphaeridium dubium Volk., B. cerinum Volk., B. ornatum Volk., B. compressum Volk., $B$. orbiculare Volk. are typical of the Lükati Beds. The complex of acritarchs found in the Kakumägi Beds is very similar to the former complex, but the number of species decreases, and only one new species appears (Tab. 1,2). No acritarchs were detected in the studied samples from the Tiskre Beds. 